\title{
Aspectos do Direito Comparado
}

\author{
Francisco Ovidio \\ Professor da Faculdade de Direito da UNAERP \\ de Ribeirão Preto e Membro da Academia In- \\ ternacional de Jurisprudência e Dir. Comparado
}

A importância do Direito Comparado tem sido destacada não só pelos juscomparativistas como, também, pelos estudiosos do Direito em geral. Constitui o seu estudo um dos planos mais significativos da Ciência Jurídica na atualidade. A pesquisa jurídica comparativista contribui de forma marcante para a evolução e o alargamento das fronteiras do conhecimento jurídico.

Especialmente na época atual, que oferece grande facilidade de comunicações, verifica-se um incessante relacionamento entre os diferentes países, quer no plano político, econômico, comercial e pessoal. Mesmo separados, muitas vezes, por diferenças de natureza ideológica, os países tendem a estreitar os laços no terreno político, em decorrência do pragmatismo imperante nas relações internacionais. A economia mundial contemporânea é marcada pela vinculação entre os sistemas econômicos das nações; as multinacionais mantêm empresas nos mais variados locais, independentemente de distâncias e posicionamentos ideológicos. A mobilidade das pessoas de um país para outro cresce a cada dia mais. Enfim, é um mundo onde o relacionamento entre os diversos países é uma nota marcante.

As formas de relacionamento acima indicados implicam na criação de mecanismos jurídicos capazes de solucionar os decorrentes problemas e no aprimoramento dos já existentes. Assim, torna-se imprescindivel o conhecimento e análise dos grandes sistemas jurídicos e dos ordenamentos jurídicos particulares das diferentes nações, o que nos conduz necessariamente aos domínios do Direito Comparado.

Frente ao relevante papel do juscomparativismo em nossos dias, destacaremos alguns aspectos do seu vasto campo de abrangência, no sentido de contribuir para uma maior divulgação da matéria e da importância do seu estudo. A abordagem será limitada aos seguintes pontos: conceituação, determinação da natureza, problema metodológico, funções e evolução (em geral e no Brasil) do Direito Comparado. 


\section{Conceito e natureza do Direito Comparado}

A definição do Direito Comparado está diretamente ligada à determinação da sua natureza, ou seja, se é uma ciência ou simplesmente um método. Neste ponto há grande divergência entre os estudiosos. De um lado, entendem que é uma ciência Lévy-Ullmann, Saleilles, Köhler, Maine, Salmon, Wigmore, Holland, Pollock, Bryce, Zweigert, Kutz, Rodière, Caio Mário da Silva Pereira e Marc Ancel, entre outros conceituados especialistas. De outro, vislumbram um simples método («Rechtsvergleichung») René David, Jescheck, Gutteridge, De Francisci, Káden e Lino de Moraes Leme, apenas para citar os mais conhecidos. Ainda, autores como Lambert consideram o Direito Comparado como ciência e como arte; Blagojevic situa que, a título instrumental, não passa de um método (a ciência seria, conseqüentemente, a instrumentalizada pelo método comparativo), enquanto que visto de forma autônoma constituiria ciência ${ }^{(4: 83 / 4)}$.

Não pretendemos nesta oportunidade, devido o caráter panorâmico deste artigo, penetrar nos argumentos desenvolvidos pelos diversos partidários de uma ou de outra tese. Assim, vamos limitar o enfoque às colocações de René David e Marc Ancel.

Em seu excelente «Traité Elementaire du Droit Civil Comparé», René David afirma que o Direito Comparado «(...) não é um ramo da ciência jurídica análogo àqueles outros ramos que nós tivemos em vista, direito civil ou direito comercial, direito administrativo ou direito penal. O direito civil, para citar um exemplo, é uma parte do direito positivo francês, ele é constituído por uma série de regras, que a doutrina e a legislação ordenam sistematicamente, e que constituem regras de conduta para os particulares nas suas relações uns com os outros; os tribunais resolvem os litígios entre os particulares impondo a observância destas regras, aplicando o direito civil.» Já o mesmo não se verifica no tocante ao Direito Comparado, pois «(..) não existem regras de direito comparado no mesmo sentido como há regras de direito civil ou de direito penal; as regras de direito comparado, se se pode empregar esta expressão, não são feitas para governar a conduta dos cidadãos, das pessoas de direito público ou do Estado; o direito comparado não é parte do direito positivo de uma determinada nação, do mesmo modo que o direito civil, o direito administrativo, ou o direito internacional privado ou público.» Assim, conclui que «o direito comparado nada mais é, realmente, que a comparação de direitos, é o método comparativo no domínio das ciências jurídicas» ${ }^{(5: 3 / 4)}$.

Por outro lado, Marc Ancel em sua obra «Utilidade e métodos do Direito Comparado; elementos de introdução geral ao estudo comparativo dos direitos», advoga a tese contrária, sustentando que o Direito Comparado é uma ciência, e aponta duas razões principais para justificar o seu entendimento. Em primeiro lugar, mostra que a preocupação de «(..) análise dos grandes sistemas jurídicos em 
vigor (...) constitui ou tende a constituir uma geografia análoga, ou, mais exatamente, paralela à história das instituições jurídicas (... ) . Esta dimensão geográfica da pesquisa comparativa revela-se, incontestavelmente, de caráter científico». Em segundo lugar, se nos preocupamos em «( ...) distinguir a utilização ocasional da comparação, e a utilização sistemática do método comparativo, percebe-se, facilmente, que esta nada mais é que o método de uma ciência que, mesmo se se admitir não ter ela objeto próprio no início, chega-se ao termo da pesquisa, a um resultado, a um produto que se torna um objeto de ciência específica» (1:50/1).

Ancel mostra que a utilização do método levará à dedução de um conteúdo científico novo, tornando-se, desta forma, «(...) a matéria de um conjunto de conhecimentos sistematicamente organizados.» Pergunta, então, o eminente comparativista: «(...) não está aí a característica fundamental de uma ciência?»

Qual das teses acima traduz, do ponto de vista epistemológico, a verdadeira natureza do Direito Comparado? Para solucionar a questão faz-se necessária a análise de alguns aspectos relacionados à definição de ciência. Para evitar maiores digressões, recorreremos a uma definição fornecida por Luís Washington Vita, que explica: «(...) modernamente se entende por ciência um conjunto de conhecimentos em torno de um determinado objeto, obtidos com determinados critérios metódicos e sistemáticos num organismo logicamente construído» (15:115).

O Direito enquadra-se perfeitamente nos termos da definição de ciência acima apresentado. $\hat{E}$, incontestavelmente, um conjunto de conhecimentos sistematicamente organizados, que têm por objeto a regulação normativa das relações sociais. Constitui o resultado de um processo de construção e elaboração de conceitos. E o Direito Comparado?

A solução da controvérsia Direito Comparado como ciência ou simples método exige a análise do problema sob um novo prisma. René David e Gutteridge, entre outros, enfatizaram a falta de um corpo definido de regras, para recusar o estatuto de ciência ao Direito Comparado. Se a questão for enfocada sob esta ótica, obviamente, que não constítuirá uma ciência como o Direito Civil, Direito Penal etc. Com efeito, não existe um corpo de regras definidas que possam ser consideradas como de Direito Comparado. Entretanto, a colocação do problema em outros termos poderá levar a um entendimento diferente.

A diferenciação das ciências entre si pode ser feita não só pelo objeto material (o conjunto de seres ou de realidades sobre que incide) como, também, pelo objeto formal (o peculiar ponto de vista sob o qual analisam esse conjunto). Nestes termos, duas ciências podem ter o mesmo objeto material e, no entanto, objetos formais diferentes. É o caso, por exemplo, da História e da Política. Ambas têm o mes- 
mo objeto material - os fatos políticos - mas, no entanto, divergem no tocante ao objeto formal. Enquanto a História trata dos fatos políticos de forma diacrônica, a Política encara-os de maneira sincrônica. O mesmo raciocínio pode ser aplicado em relação ao Direito Comparado e à Ciência do Direito. O primeiro «(...) estuda o direito comparando sistemas jurídicos diferentes e figuras e institutos diferentes (...), já a segunda estuda o direito dogmático, pela construção de categorias num todo sistematizado e pelo estabelecimento de relações entre categorias definidas ${ }^{(4: 79 / 81)}$.»

Ainda, para reafirmar o estatuto científico do Direito Comparado, é conveniente trazer à tona mais uma vez a análise efetuada por Marc Ancel. A cientificidade do Direito Comparado, no seu entender, liga-se à dimensão geográfica da pesquisa comparativa e ao emprego sistemático do método comparativo, que possibilitam a produção de um conteúdo novo. As duas ordens de preocupações determinam o surgimento de um conjunto de conhecimentos sistematicamente organizados, que é um dos traços essenciais da ciência.

A tarefa de agrupar os diversos sistemas jurídicos em famílias também revela o caráter científico do Direito Comparado, uma vez que, conforme destaca Constantinesco, «(...) uma ciência é antes de mais nada um sistema de classificação.» Por outro lado, a comparação dos diversos sistemas jurídicos entre si favorece a elaboração de «sínteses conceituais», de enorme importância na abordagem científica da matéria.

O Direito Comparado atende, assim, aos requisitos substanciais da ciência: conhecimentos adquiridos de maneira metódica, sem o caráter de improvisação; validade universal dos conhecimentos produzidos; e que esses conhecimentos tenham passado pelo crivo da observação sistemática. A utilização do método comparativo preenche o primeiro requisito; as «sinteses conceituais» operadas pela atividade juscomparativista podem ser aplicadas no estudo dos diferentes ordenamentos jurídicos do passado ou da atualidade, cumprindo com o segundo requisito; enquanto que a utilização dos métodos e procedimentos consagrados pela ciência jurídica comparativista garante a observação sistemática dos fatos. Por último, não deixa de ser oportuna a lembrança das observações de Zweigert, de que «(...) dentro dos quadros do direito, o direito comparado é a única ciência», bem como a de Kutz, para quem «nenhum estudo merece o nome de ciência se se limita a fenômenos que se verificam dentro das suas fronteiras naturais $(\ldots)$. O direito comparado oferece a única via pela qual o direito pode tornar-se internacional e conseqüentemente uma ciência ${ }^{(4: 82-3)}$.»

Uma vez analisada a questão referente à natureza do Direito Comparado devemos, então, abordar a sua definição. Muitas são as conceituações, decorrentes da ótica peculiar, através da qual o estudioso enfoca a matéria. Já vimos que René David considera que «(...) nada mais é, realmente, que a comparação de direitos, é o 
método comparativo aplicado no domínio das ciências jurídicas», posição esta adotada por diversos especialistas. No «Vocabulaire Juridique», elaborado sob a direção de Henri Capitant, é definido como « (...) o ramo da ciência do direito que tem por objeto a aproximação sistemática de instituições de diversos países ${ }^{(1: 43)}{ }^{(»}$ Sujiyama sustenta que «(...) a ciência do direito comparado é uma das disciplinas da ciência do direito supranacional, fundada no novo direito natural, que tem por objeto realizar o progresso comum do direito mundial, mediante a comparação positiva e a aproximação sistemática dos direitos, e em caso necessário, pela construção jurídica.» Martínez Paz afirma que «(...) é a disciplina jurídica que se propõe, por meio da investigação analítica, crítica e comparativa das legislações vigentes, descobrir os princípios fundamentais relativos e o fim das instituições jurídicas e coordená-las num sistema de direito positivo atual ${ }^{7: 39)}$.»

As diferentes definições, que não se esgotam nas apresentadas acima, traduzem de forma nítida o posicionamento epistemológico dos seus elaboradores. Para René Davi não passa de um método, o método comparativo aplicado à Ciência do Direito, para o «Vocabulaire Juridique» de Capitant constitui ramo da ciência jurídica, no que é seguido por Sujiyama (disciplina da ciência do direito supranacional) e por Martínez Paz. Sujiyama situa o fundamento ontológico do Direito Comparado «num novo direito natural». Martínez Paz limita-o à investigação das legislações vigentes, não se preocupando com as passadas. Como se percebe, variam as características das diversas definições, mas apresentam um certo fundo comum: a aproximação dos diversos direitos, a descoberta de princípios comuns entre eles, o aperfeiçoamento e a elaboração de um possivel sistema único.

Da nossa parte, podemos considerá-lo como a disciplina cientifica que tem por objeto o estudo comparativo-sistemático de instituições ou sistemas jurídicos diversamente situados no espaço ou no tempo, com a finalidade de estabelecer os pontos comuns e as diferenças existentes entre eles, para compreender a sua evolução e determinar os parâmetros para o seu aperfeiçoamento e reforma.

\section{Funções do Direito Comparado}

O Direito Comparado era visto até certo tempo como uma preocupação despretensiosa, de mero diletantismo intelectual. No entanto, com o amadurecimento científico da matéria, os estudos realizados pelos especialistas, a promoção de congressos nacionais e internacionais dedicados ao tema e o aparecimento de instituições científicas, revelaram-se as suas finalidades, que comprovam o seu caráter prático e instrumental, bem como as suas repercussões não só na Ciência do Direito, como, também, no plano político, econômico, etc. René David sintetizou as suas vantagens nos seguintes termos: « ( . . ) é útil nas investigações históricas ou filosóficas respeitantes ao direito; é útil para melhor conhecer e aperfeiçoar o 
direito nacional; e, finalmente, útil para compreender os povos estrangeiros e estabelecer um melhor regime para as relações da vida internacional ${ }^{(6: 28)}$.»

O Direito Comparado preocupa-se, inicialmente, com a comparação de sistemas jurídicos particulares de diferentes países, destacando os seus pontos comuns ou distintivos, o que constitui a «macrocomparação». Por outro lado, pode limitar a sua atividade à comparação de determinados institutos jurídicos pertencentes a ordens jurídicas distintas, por exemplo, o contrato no Direito Brasileiro e no Direito Italiano, o que representa a «microcomparação».

A atividade juscomparativa foi, paulatinamente, ampliada no sentido de não se limitar à comparação de normas jurídicas, mas, também, de ciências jurídicas, procurando captar os diferentes tratamentos conceituais do fenômeno jurídico e as relações existentes entre o Direito e a realidade social subjacente.

Com efeito, o Direito Comparado tem objetivos específicos, como o de possibilitar uma melhor compreensão do espírito que anima as instituições jurídicas, as técnicas vigentes na época e responder indagações existentes no tocante à gênese dos sistemas jurídicos primitivos; objetivos práticos, notadamente no tocante aos esforços de unificação do Direito Privado no plano internacional e à solução dos conflitos de leis no Direito Internacional Privado; objetivos políticos, pois no mundo atual é impossivel pensar em «muralhas chinesas» separando os sistemas jurídicos dos países, mesmo dos ideologicamente conflitantes, contribuindo, assim, o esforço comparativista para um melhor entendimento no plano das relações internacionais. No dizer de Constantinesco, a tendência dos estados não é no sentido de constituírem unidades fechadas, que intitula de «perspectiva ptolemaica», mas, sim, de ampliarem as suas relações com os demais, ou seja, a «perspectiva coperniciana».

No mundo atual, em que pesem os antagonismos ideológicos, a tendência das relações internacionais orienta-se no sentido da aproximação entre os países, de uma vinculação necessária, o que, por sua vez, implica na criação e no desenvolvimento de mecanismos jurídicos para disciplinar o relacionamento e dirimir os inevitáveis conflitos de interesses. No plano regional, o surgimento de organização como o Mercado Comum Europeu, a Associação Latino-Americana de Livre Comércio, a Benelux, a Comunidade Européia do Carvão e do Aço, entre outras, possibilitou a criação de um «direito comunitário», de um «direito de integração». Fala-se, também, de um «direito transnacional».

Para muitos comparativistas a unificação do direito constitui a função básica do Direito Comparado. De um lado, a unificação do direito representa uma aspiração, uma meta a ser atingida no futuro. De outro, indica a série de iniciativas que objetivam a concretização desse ideal. O movimento pela unificação do direito procurou, ini- 
cialmente, atingir a unificação de regras, evoluindo, posteriormente, para o nível de princípios, ou de «standarts» gerais de comportamento. Segundo Marc Ancel, «essa evolução implica, sob a ótica comparativa, em conseqüências importantes, que serão, simplesmente, enunciadas brevemente:

- a unificação de regras deixa de ser o objetivo principal do direito comparado e a preocupação maior do comparativista;

- a harmonização, coordenação, até mesma a uniformização são viáveis entre sistemas e entre matérias onde a unificação das regras seria de difícil realização;

- evolui-se, por conseguinte, da antiga unificação para a nova uniformização: uma vez mais, o caminho científico consiste em superar a regra para atingir o sistema; e, uma vez mais também, ele consiste em considerar o sistema como um todo, nos seus métodos e no seu espírito ${ }^{(1: 104)}$.»

A unificação está, no entanto, mais restrita ao campo do Direito Privado e do Direito Processual Civil. No âmbito latino-americano registraram-se esforços no sentido do estabelecimento de um código tributário modelo, de um código penal típico e de um código aeronáutico. Inclusive, deve ser mencionado o trabalho desenvolvido durante as «Jornadas Latino-Americanas de Direito Processual», realizadas em diversos países do continente.

\section{3. $\mathbf{O}$ aspecto metodológico}

Após analisarmos a controvérsia sobre a natureza do Direito Comparado, verificamos que o mesmo constitui uma ciência. E, como toda ciência pressupõe um método, qual será, então, o método apropriado para o seu estudo? O método histórico, o funcional, o dialético, o exegético, o social, o indutivo, o dedutivo, o dogmático ou o estrutural. Enfim, todos os disponíveis no vasto arsenal metodológico e aplicáveis ao estudo do Direito.

Já está sobejamente demonstrada a necessidade e a importância do método na atividade científica. A sua correta utilização garante ao pesquisador de qualquer campo do conhecimento penetrar no objeto de estudo e atingir a essência do fenômeno para explicá-lo ou compreendê-lo. Ortega y Gasset situou lapidarmente o relevante papel da opção metodológica na prática científica ao colocar a seguinte questão: "Queda usted en entera libertad de elegir entre dos cosas: o ser filósofo o ser sonámbulo». O recurso ao método apropriado para determinada fase da pesquisa livra o estudioso da embaraçosa situação sonambúlica característica dos que se afastam deste pressuposto essencial da atividade científica.

O estádio atual de desenvolvimento da Epistemologia revela que o método não deve ser encarado como uma bitola estreita, que condi- 
ciona e limita a liberdade do pesquisador. Antes, deve constituir um campo aberto para discussões e críticas, flexível e retificável a cada etapa da elaboração científica. Portanto, não se concebe mais as iniciativas no sentido de se privilegiar certo(s) procedimento(s) metodológico(s) em detrimento de outros existentes, sob a alegação de ser $(\mathrm{em})$ mais ou menos científico(s), pois os métodos se interagem e se completam na prática científica. A palavra de ordem na atualidade é o «pluralismo metodológico».

Esta posição é compartilhada por destacados juscomparativistas contemporâneos, como Gino Gorla e Marc Ancel, que postulam para cada categoria de problemas comparativos um determinado método. Ainda, deve se ressaltar que a própria utilização do método está na dependência das fontes de informações disponiveis (1:115). Ancel mostra que, ao nível da regra de direito, o método indicado será o infor. mativo ou descritivo; ao nível do sistema, será o estrutural; tratando-se de instituição, será principalmente o técnico ou, em certos casos, - tecnicista. Propõe, ainda, revelando uma indisfarçável preferência, um outro ponto de partida - o de uma situação de fato determinada - que se liga ao «law in action», para justificar o emprego do método funcional.

A pesquisa conduzida pelo método funcional, no entendimento do renomado juscomparativista francês, apresenta certas vantagens, pois faz « (...) surgir a possibilidade de estudar o mesmo assunto em sistemas sócio-políticos totalmente diferentes (...) e revela a (...) interdependência das ciências humanas, permitindo uma abordagem ou um estudo que torna-se, poderíamos dizer, de certo modo metajurídico» (1:114/121).

A reflexão metodológica deve ser ampla e pluralista para atender à dinâmica da ciência, e não limitada ao estéril sectarismo metodológico. Dizer aprioristicamente que o procedimento deva ser este ou aquele não se mostra como uma postura científica. Somente no processo de elaboração teórica, e em face do objeto de conhecimento, é que será possível a definição sobre o(s) método(s) mais indicado(s).

\section{A evolução do Direito Comparado}

A preocupação comparativista no Direito remonta à Antiguidade Grega, com Licurgo e Sólon, respectivamente, em Esparta e Atenas, que viajaram o mundo da época para conhecer as instituições estrangeiras antes de legislar. Platão, em «Nomoi», comparou as normas jurídicas das cidades gregas, bem como analisou os seus fundamentos filosóficos e metafísicos. Teofrasto efetuou um estudo descritivo-comparativo do direito privado da época. Já Aristóteles afirmou o princípio de que não há ciência do particular e analisou cento e cincoenta e oito constituições das «poleis» e cidades bárbaras, particularmente a cartaginesa. 
Em Roma, os decênviros, elaboradores da «Lei das XII Tábuas», levaram em conta as legislações existentes na época, particularmente a grega, em sua tarefa legislativa. No século $\mathrm{V}$ da nossa era, encontramos a "Collactio Legum Romanorum et Mosaicarum», um trabalho comparativo das duas legislaçōes básicas do mundo antigo: a romana e a hebráica. No século XV, deparamos com o «De Laudibus Legum Angliae», de Fontescue, na Inglaterra; Fulbeck escreveu uma obra em forma de diálogo entre um jurista inglês, um canonista e um romanista, intitulada "The parallele of Conference of the Civil Law, the Canon Law and the Canon of this Realm of England»; St. Germanin, na mesma linha de apresentação, publicou «Doctor and Student», uma discussão entre um jurista romanista e um inglês.

Embora, conforme verificamos, os primeiros esforços juscomparativistas possam ser localizados na Antiguidade, algumas razões impediram o desenvolvimento da sua feição científica. No entendimento de René David, a tendência da Ciência Jurídica até o século XIX era a de revelar « (...) os princípios e soluções dum direito justo, conforme a vontade de Deus, à natureza e à razão. Ela está dissociada dos direitos positivos.» Foi a época do primado do Direito Natural, colocado acima dos ordenamentos positivos, que acarretou uma dicotomia entre o Direito Natural e o Direito Positivo. Segundo o eminente comparativista francês, havia nos ambientes universitários um desprezo em relação ao estudo dos costumes e das Ordenanças, preocupando-se apenas com « $(\ldots)$ o ensino da verdadeira ciência do direito, o método pelo qual se poderiam em todos os países, descobrir as soluções de justiça» (6:26), o que seria alcançado através do estudo do Direito Romano e do Direito Canônico, vistos como o «jus commune» do mundo civilizado. Esta postura representou um «obstáculo epistemológico» na evolução do Direito Comparado, retardando o processo de formação do seu campo de conhecimentos autônomo. Só a partir do século XIX, com a divulgação desse direito comum e a sua substituição pelas codificações nacionais, é que se tornou possível o desenvolvimento científico da matéria.

No processo evolutivo da doutrina juscomparativista podem ser distinguidas quatro fases progressivas que, não obstante se interpenetrarem em certos aspectos, apresentam características próprias, a saber:

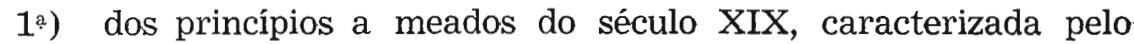
exame e tradução da legislação estrangeira;

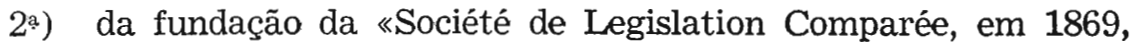
até o fim do século XIX, cuja tônica foi o estudo da legislação com. parada, a análise paralela e organizada das leis estrangeiras e nacionais;

$3^{\text {a) }}$ do início do século XX (Congresso Internacional de Direito Comparado, em 1900, em Paris), com o aperfeiçoamento e ampliação do trabalho comparativo; 
4.) a partir da fundação da «Académie Internationale de Droit Comparé», em Haia, em 1924, prolongando-se até os dias atuais, com a internacionalização do Direito Comparado ${ }^{(14: 409)}$.

A criação da cadeira de «História Geral e Filosofia da Legislação Comparada», em 1830, no Collège de France, sob a direção de Leminier, representou o reconhecimento da importância e da necessidade do estudo do Direito Comparado. Anos depois, em 1837, surgiu outra cadeira na Faculdade de Direito de Paris, orientada por Ortolan. Nesta primeira fase, a preocupação principal era o exame da legislação estrangeira, com a trađução de obras, a análise e a divulgação dos códigos e textos legais de outros países. A divulgação da matéria foi feita principalmente em duas importantes revistas: «Krit Zeit für Rechtswissenchaft und Gesetzgebung des Auslandes», criada por Mittermaier e Zacharie, na Alemanha, que funcionou de 1829 a 1856, e a «Revue Étrangere de Legislation», depois, intitulada «Revue Étrangere et Française de Legislation et Economie Politique» (1835 a 1850).

O desenvolvimento do comércio internacional, o incremento das relações humanas, dos meios de comunicação e o espírito científico da época criaram condições favoráveis para uma nova postura comparativista. Assim é que, em 1869, apareceram na França, a «Société de Legislation Comparée», fundada por Laboulaye; na Inglaterra, a cadeira de «Historical and Comparative Law», em Oxford, regida por Henry Summer Maine; na Bélgica, a «Revue de Droit International et de Droit Comparée» e, na Itália, Emerico Amari publicou uma «Critica di una scienza delle legislazioni comparate». Inclusive no Japão verificou-se o incremento dos estudos comparativistas, pois com a ocidentalização do país, a partir de 1868, promoveu-se a tradução dos códigos franceses para servir de base a uma nova codificação e chegaram os primeiros juristas ocidentais às universidades locais. E a segunda fase do comparativismo moderno, na qual o estudioso «( .. ) compara as leis, anotando as semelhanças, diferenças e relações; já é o desfile organizado das leis nacionais e estrangeiras ${ }^{(13: 490 / 1)}$.»

No começo do século atual, em 1900, por ocasião da Exposição Internacional de Paris, a «Société de Legislation Comparée» promoveu um Congresso Internacional de Direito Comparado, com a participação dos maiores juristas da época (dentre eles, Saleilles, Lambert e Pollock), cuja influência foi decisiva para o desenvolvimento do movimento juscomparativista e a formação do campo de conhecimentos científicos da disciplina. Saleilles, no relatório de síntese, fez um balanço do caminho percorrido pela entidade desde a fundação: «A vulgararização da vida jurídica particular dos povos civilizados, que segundo ele, assinalava o período de 1869, é conveniente substituir por uma ciência nova, «a ciência do direito comparado, no sentido jurídico da palavra», disciplina nova, «independente e autônoma», tendo por objeto «deduzir do conjunto das instituições particulares um fundo comum, ou ao menos pontos de aproximação suscetiveis de fazer 
transparecer, sob a diversidade aparente das formas, a unidade profunda da vida jurídica universal ${ }^{(1: 25)}$.»

A criação de institutos dedicados ao estudo do Direito Comparado passou, então, a se verificar nos principais centros jurídicos, inicialmente, europeus, depois, estendendo-se para outras regiões. Sem a preocupação de fornecer uma enumeração exaustiva, podemos registrar a «Académie Internationale du Droit Comparé, em 1924, em Haia, um dos marcos mais significativos na evolução do Direito Comparado; o "Institut du Droit Comparé», em Lyon, criado por Lambert; o de Paris, fundado por Lévy-Ullmann; o «Instituto de Studi Legislativi», instalado na Itália, em 1924, por Galgano e Sarfatti; a «Internationale Vereinigung für vergleichende Rechtswissenschaft und Volkswirtschaftlehre e Gasseschaft für vergleichende Rechts und Staatwissenshaft», na Alemanha; o «Bureau of Comparative Law», anexo à "American Bar Association», nos Estados Unidos; o «Instituto Americano de Derecho y Legislación Comparada», na Espanha; a «Academía Interamericana de Derecho Comparado e Internacional», em Havana, 1945, reinstalada mais tarde no Rio de Janeiro, em 1974, sob a presidência de Haroldo Valladão.

Após a Segunda Guerra Mundial, merece destaque a fundação do «Comité International du Droit Comparé» (desde 1954 «Association Internationale des Sciences Juridiques»), com o objetivo de «(...) promover a compreensão e o conhecimento recíproco das nações, e ajudar no aumento do saber, encorajando em todo o mundo o estudo de sistemas jurídicos estrangeiros e o uso do método comparativo na ciência do direito», ligado à UNESCO, e que tem contribuído de forma notável para o desenvolvimento do comparativismo jurídico. Congrega comissões nacionais de Direito Comparado de aproximadamente cincoenta países, com um comitê diretivo integrado por nove membros, que representam os diversos sistemas jurídicos do mundo e que são eleitos pelo conselho constituído por um representante de cada associação nacional filiada. Em nosso país, recebeu a denominação de «Comitê Nacional de Direito Comparado», fundado em 1948, por Haroldo Valladão, junto à Faculdade Nacional de Direito.

A atividade desenvolvida pela «Académie Internationale du Droit Comparé» de Haia tem sido notável. Nos diversos congressos realizados, inclusive com a participação de representantes brasileiros, dentre os quais avulta a figura do Prof. Haroldo Valladão, em Paris (1954), Bruxelas (1958), Hamburgo (1962), Upsala (1966), Pescara (1970), Teerã (1974) e Budapeste (1978) efetua-se o intercâmbio de idéias através das teses apresentadas, que não só atestam o amadurecimento científico da matéria como, também, contribuem para o seu maior desenvolvimento e divulgação. No Congresso de 1932, presidido por Bustamante y Sirvén, foi aprovado, entre outras matérias, um voto para a criação de uma Faculdade Internacional de Direito. Só em 1958, ocorreu o início das atividades da Universidade Internacional de Ciências Comparadas, com a inauguração do Instituto Uni- 
versitário Internacional Luxemburgo, que passou a oferecer cursos e conferências sobre o assunto aos interessados dos diferentes países.

A fase atual do Direito Comparado tem como característica a «(...) plena internacionalização do direito comparado, graças às reuniōes e organismos internacionais específicos, que conduzem à universalização do direito comparado ${ }^{(13: 490 / 1)}$.» Apenas para citar alguns dos mais importantes institutos que se dedicam ao estudo e divulgação da matéria juscomparativista, mencionaremos a «Academia Internacional de Direito Comparado» (Haia), a «Associação Internacional de Ciências Jurídicas» (ligada à UNESCO, com sede em Paris, que está publicando a «International Encyclopedia of Comparative Law»), o UNIDROIT (Instituto Internacional para a Unificação do Direito Privado, com sede em Roma), a UNCITRAL (ou CNUDCI. Comissão das Nações Unidas para o Direito Comercial Internacional), o Max Planck Institut (Alemanha Federal) e a centenária Société de Législation Comparée (França, que publica a excelente Revue Internationale de Droit Comparé). No campo universitário cabe registrar a Faculdade para o Ensino do Direito Comparado, em Estrasburgo; o Instituto Universitário Internacional Luxemburgo, acima mencionado, e o Instituto Universitário Europeu, de Florença. A atividade destas instituições tem possibilitado um crescente desenvolvimento da doutrina comparativista e a internacionalização dos seus princípios científicos.

O nivel atingido pela ciência juscomparativista tem descortinado aos estudiosos do Direito novas perspectivas de análise dos sistemas jurídicos. $\mathrm{O}$ enfoque tradicional, caracterizado pelo maniqueismo «direitos latinos» versus «direitos germânicos» foi paulatinamente superado com o reconhecimento da importância do «common law» e dos sistemas jurídicos emergentes da África e da Ásia.

O advento dos regimes autoritários na Europa e a eclosão da Segunda Guerra Mundial provocaram uma crise no comparativismo jurídico, logo em seguida, acentuada pela bipolarização do mundo em dois blocos políticos antagônicos - países comunistas e países capitalistas. No entanto, a evolução da política mundial e os esforços dos juscomparativistas e das organizações dedicadas ao assunto possibilitaram notáveis progressos no sentido da eliminação dos obstáculos e duma aproximação cada vez maior de sistemas jurídicos de países, mesmo dos separados ideologicamente.

$\mathrm{Na}$ atualidade, o Direito Comparado constitui um dos pontos culminantes dos estudos e pesquisas jurídicas; o seu caráter instrumental faz com que a cada dia aumente a sua importância. Quem sabe, no futuro, será possivel realizar a unificação dos direitos, que na atualidade muitos colocam como uma utopia? Já existem as normas de «direito uniforme», incluídas nos ordenamentos jurídicos de diferentes países, cuja utilização poderá ser ampliada ainda mais. Também a integração regional dos países determina o aparecimento do direito comunitário», do «direito de integração». A unificação dos direitos, considerada como um dos objetivos da «Académie Internationale du 
Droit Comparé», e reafirmada por Lévy-Ullmann, em 1925, ao apregoar a necessidade da construção do «direito mundial do século XX», poderá ser atingida com o passar do tempo.

\section{O Direito Comparado no Brasil}

As raízes do comparativismo brasileiro podem ser encontradas em Portugal. A Lei da Boa Razão (1769), elaborada por iniciativa do Marquês de Pombal, determinou que para a aplicação do Direito Romano devia-se recorrer ao subsídio próximo das « (...) Nações Cristãs iluminadas e polidas, que com elas estão resplandecendo na boa, sã e depurada jurisprudência.» Ainda, no seu parágrafo nove, estabelecia como critério para revelar a boa razão a noção que dela se dá nas leis políticas, econômicas, mercantis e marítimas.

O conhecimento das instituições políticas e jurídicas de outros países, notadamente das idéias francesas e da experiência norte-americana, serviu de inspiração para os participantes do movimento da Conjuração Mineira, em 1789. Nas bibliotecas dos principais líderes figuravam obras da literatura política e jurídica de outras nações, notadamente a Constituição Americana.

A independência política do Brasil, em 1822, exigiu a implantação de medidas no sentido de consolidá-la em outros setores, inclusive no cultural. Assim, logo em 1825, foi aprovada a criação de uma faculdade de Direito na Capital do Império, sendo encarregado o Visconde de Cachoeira da tarefa de elaborar os seus estatutos. Entretanto, o curso não chegou a funcionar. Só em 1827, com a instalação dos cursos jurídicos de São Paulo e Olinda, é que a aspiração alimentada há tempos pelos brasileiros acabou sendo concretizada.

Os Estatutos do Visconde de Cachoeira passaram a regular a vida acadêmica dos recém-criados cursos. Dentre os seus dispositivos indicava-se a explanação do uso moderno do Direito Romano, bem como «( ...) o exame da jurisprudência análoga das nações polidas», reproduzindo o que já preconizava a Lei da Boa Razão. Inclusive, era exigido do candidato ao ingresso o conhecimento do idioma francês, para que pudesse estudar nos livros franceses.

Essa época, conforme explica Haroldo Valladão, correspondeu à primeira fase do comparativismo, ou seja, do exame e tradução da legislação estrangeira. Não só nas faculdades como, também, nos tribunais, na administração pública e no parlamento, a tendência era a utilização das obras jurídicas estrangeiras e a adoção dos códigos das nações em evidência na época. Os mais destacados juristas do Império, como Teixeira de Freitas (considerado por René David «o Savigny americano»), Lafayette, Ribas, Bernardo de Vasconcelos, Pimenta Bueno, Tobias Barreto, entre outros, utilizaram em suas aulas e na elaboração das suas obras, muitas delas clássicas em nossa literatura jurídica, a doutrina estrangeira. Tobias Barreto, apenas para citar um dos casos, constitui um modelo acabado dessa postura. Apai- 
xonado pela cultura alemã, aprendeu sozinho a língua germânica e devorou, por assim dizer, os principais autores como Jhering, Post, Noiré, Gneist, Hartmann, Lazarus e Steinthal, possibilitando a abertura de uma nova linha de pensamento filosófico e jurídico em nosso País. Em torno de si, congregou um grupo de discípulos, integrantes da chamada Escola do Recife, que um pouco mais tarde marcaria a cultura brasileira, dentre os quais Clóvis Beviláqua, autor do ante-projeto do Código Civil vigente.

O Decreto $\mathrm{n}^{\circ} \mathbf{7 . 2 4 7}$, de 19 de abril de 1879 , prescreveu que «( . .) o estudo do Direito constitucional, criminal, civil, comercial e administrativo será sempre acompanhado da comparação da legislação pátria com a dos povos cultos.» Já o de número 9.360, de 17 de janeiro de 1985, criou a cadeira de «direito privado comparado», que só foi instalada com a Reforma Benjamin Constant (1891).

Na Academia de São Paulo a cadeira coube a João Monteiro; na de Recife, a Clóvis Beviláqua; e no Rio de Janeiro, na Faculdade Livre de Direito, ao Conselheiro Cândido Luis Maria de Oliveira. Estes três nomes contribuiram de forma marcante para a evolução do Direito Comparado no Brasil, pois senhores de cultura jurídica invulgar, não só em suas obras, mas, também, na atividade docente, promoveram a divulgação dos princípios básicos do juscomparativismo na época.

As preleções de Clóvis Beviláqua, inicialmente publicadas na Revista Acadêmica da Faculdade de Direito do Recife, em 1891, posteriormente, resultaram na obra «Resumo das lições de legislação comparada sobre direito privado». Clóvis mostrou que a aplicação do método comparativo pode situar-se no espaço e no tempo. A comparação no tempo constituirá o «( . ) estudo histórico e comparado do direito em gênero, ou de qualquer de seus institutos, desde a sua gênese indefinida e incoerente até suas últimas especialidades e abstrações desatadas à tona do pensamento moderno. A primeira parte deste estudo forma essa ordem de indagações atraentes que foi, com toda propriedade, chamada paleontologia jurídica. A segunda parte formará a história do direito propriamente dita, sua filogenia, ou poderá ser o estudo ontogenético de um direito ou mesmo de um agrupamento natural de institutos sob a luz da comparação.» Quanto à comparação no espaço, confrontando os diversos ordenamentos jurídicos vigentes $\ll(.$. . ) e procurando, sob o frio tecido tegumentar das leis, surpreender os estos da vida humana, constituirá o complemento da jurisprudência etnológica $(\ldots)^{(3: 22)}$.»

João Monteiro, em sua aula inaugural da cadeira (1892), discorreu sobre o tema «Da futura universalização do Direito» e, posteriormente (1895), publicou um artigo «Cosmópolis do Direito», na Revista da Faculdade de Direito de São Paulo. Nesse trabalho, Monteiro vislumbrava «( . . ) no futuro, que esta febril contemporânea renovação social vai a passos largos encurtando, não haverá grupos da civilização, mas a civilização humana, e com a unidade política 
virá a universalização legislativa, e o mundo inteiro se chamará a «Cosmópolis do Direito». Aquilo que a «Académie Internationale du Droit Comparé» consagraria, em 1924, entre os seus objetivos, ou seja, a unificação do direito, e que Lévy-Ullman reafirmaria, em 1925, João Monteiro já preconizava em 1895. Anos depois, em 1900, no Congresso Jurídico Americano, o ilustre professor das Arcadas apresentou uma memória intitulada «Unidade do Direito», na qual afirmava que $\ll(\ldots)$ o mais poderoso elemento conservador da unidade nacional seria a unidade do direito, que o fracionamento da pátria ou a sua depauperação estaria na razão direta da separação legislativa (...) a universalização do direito era apenas uma aspiração humana; a unidade do direito nacional era, pois, necessidade prática de atualidade imperiosa ${ }^{(8)}$.»

Cândido Luís Maria de Oliveira, além das suas notáveis aulas, publicou, em 1903, o "Curso de Legislação Comparada», obra de grande profundidade em matéria juscomparativista que, no entender de Haroldo Valladão, foi precursora de modernas concepções do método comparativo no Direito. Também René David dedicou referências elogiosas à sua obra.

A reforma do ensino de 1901 suprimiu o ensino da cadeira de Legislação Comparada, mas o interesse pela matéria permaneceu aceso no meio jurídico nacional. Só com a Reforma Francisco Campos, em 1931, é que foi reintroduzida, desta vez no curso de doutorado. No Rio de Janeiro, Virgílio de Sá Pereira e Roberto Lyra assumiram a responsabilidade das aulas, enquanto que no Recife coube a A. Andrade Bezerra, e em São Paulo a Ernesto Moura e Spencer Vampré.

O interesse pelo Direito Comparado possibilitou o aparecimento de estudos de alto nível, como o «Código Civil dos Estados Unidos do Brasil Comparado, Comentado, Analisado», de autoria de A. Ferreira Coelho (publicado entre 1922 e 1933), «Direito Comparado-Direito Internacional-Direito Uniforme», de Ilmar Penna Marinho (1939), e o «Tratado de Direito Civil Brasileiro», de Eduardo Espínola e Eduardo Espínola Filho (publicado entre 1939 e 1941).

No periodo da Segunda Guerra Mundial houve um declínio dos estudos comparativistas no Brasil, como ocorreu nos demais países. Mas, um fato merece registro nessa época: a vinda para o Brasil do jurista italiano Tullio Ascarelli. A sua atividade didática na Faculdade de Direito de São Paulo deixou marcas indeláveis na história da tradicional instituição de ensino superior. Ascarelli era um profundo conhecedor dos direitos estrangeiros, notadamente do direito anglo-germânico, e, em pouco tempo, assimilou o espírito do direito brasileiro. Em 1945, publicou a obra «Problemas das Sociedades Anônimas e Direito Comparado», na qual dedicou a parte introdutória ao estudo intitulado «Premissas do Estudo de Direito Comparado». A sua preocupação era a de situar o fenômeno jurídico em seu contexto histórico e sociológico, mostrando que na tarefa interpretativa há de 
se considerar as «premissas implícitas» de todo sistema jurídico. No seu entender, tais premissas não aparecem com evidência aos juristas nacionais, devido ao fato de se incorporarem completamente à vida do Direito. Somente o estudioso estrangeiro é que poderá revelá-las com maior facilidade ${ }^{(2: 13)}$.

O ressurgimento do ensino do Direito Comparado, que fora suprimido logo após a sua reintrodução no curso de doutorado pela Reforma Francisco Campos, ocorreu em 1948, época em que Haroldo Valladão, A. Medeiros da Fonseca, José Ferreira de Souza, Roberto Lyra, Pedro Calmon, entre outros conceituados juristas, assumiram a responsabilidade de ministrá-lo nas Faculdades da Capital da República. Nos demais Estados, diversas faculdades incluíram no currículo de pós-graduação a matéria juscomparativista: em São Paulo, coube a responsabilidade a Lino de Morais Leme (que, em 1962, publicou «Direito Civil Comparado»); na Bahia, a Orlando Gomes; no Ceará, a João Perboyre Silva; no Paraná, a Oscar Martins Gomes; e, em Minas Gerais, a Caio Mário da Silva Pereira. Este último publicou diversos trabalhos sobre a matéria, sendo um deles «O Direito Comparado e o seu estudo», onde apresentou uma visão panorâmica sobre aspectos históricos, a natureza, a técnica e aspectos didáticos do Direito Comparado. Justifica a sua posição de considerar o Direito Comparado como ciência, «(. ) por não limitar sua atuação apenas à comparação de direitos, mas procurar, através da comparação, a obtenção de resultados, de finalidades, e de objetivos que lhe são próprios ${ }^{(11: 532)}$.»

E de se destacar o valioso trabalho desenvolvido pelo «Comitê Nacional de Direito Comparado». A iniciativa da sua instalação no Brasil coube a Haroldo Valladão, em 1948, com a colaboração de expressivas figuras do meio jurídico pátrio. Segundo o abalizado testemunho do seu fundador, a entidade promove reuniões anualmente de abril a dezembro, durante as quais são desenvolvidos estudos, debates e conferências, com a participação de juristas, professores e doutorandos, oriundos dos mais variados Estados e de outras nações. O Comitê tem se feito presente nos diversos congressos internacionais de Direito Comparado, nos quais os representantes brasileiros apresentaram contribuições do mais alto nível. Em seu artigo «O ensino e o estudo do Direito Comparado no Brasil», Valladão fornece a indicação dos trabalhos apresentados até o congresso de 1966, o que possibilita aquilatar a variedade de assuntos e o valor da produção científica dos comparativistas nacionais.

Em 1956, Cláudio Souto defendeu tese de doutoramento na Faculdadé de Direito do Recife sob o título: «Da Inexistência Científico-Conceitual do Direito Comparado (Conceituação do indagar comparativo mais específico da ciência do Direito). Em trabalho posterior, «Introdução ao Direito como Ciência Social», Souto retoma o assunto para reafirmar a inexistência de um Direito Comparado, colocando o problema da seguinte forma: «Parece lógico denominar aquilo que 
é tradicional e inadequadamente chamado de Direito Comparado, tão só de investigação comparativa mais específica da ciência jurídica. $\mathrm{E}$ «investigação mais específica», porque ela é a determinante do jurídico, enquanto a comparação entre o jurídico e o social pressupõe a determinação do primeiro. Ou, ainda, se se prefere, a denominação mais simples, comparação determinante do jurídico, será aceitável.» A investigação comparativa mais específica da ciência do direito é, para Cláudio Souto, «( . . . ) o estudo científico-dikelógico de princípios positivados ou de positivação possível em sistemas de conteúdos normativos de formas de coercibilidade ${ }^{(12: 152 / 3)}$.»

José Nicolau dos Santos, professor da Faculdade de Direito da Universidade do Paraná, publicou, em 1962, um estudo sobre «Direito Comparado e Geografia Jurídica», no qual procurou analisar as relações entre as duas matérias, acentuando as afinidades de métodos, objetivos e história comum. Considera o Direito Comparado como um « (...) simples método, quando muito uma ciência auxiliar», enquanto que a Geografia Jurídica preocupa-se « (...) em interpretar o fenômeno jurídico, que é o condicionamento ético-normativo da vida social, em suas relações permanentes com o meio antropogeográfico, que é o condicionamento material da sociedade ${ }^{(10: 550)} . »$

Em 1974, foi reinstalada no Rio de Janeiro, sob a presidência de Haroldo Valladão, a «Academia Internacional de Derecho Comparado» que, após a sua fundação em Havana (1945), fora transferida, em 1963, para Lima e, por fim para a ex-Capital da República.

O ensino do Direito Comparado é, atualmente, desenvolvido nos cursos de pós-graduação. Entre outras, a Faculdade de Direito da Universidade de São Paulo oferece disciplinas como «Direito Constitucional Comparado» (Prof. Manoel Gonçalves Ferreira Filho), «Direito Administrativo Comparado» (Prof. José Cretella Júnior), «Direito Tributário Comparado» (Prof. Ruy Barbosa Nogueira) e, dentro do Direito Comercial, «As projeções da empresa no Direito Comercial Comparado» (Prof. Waldírio Bulgarelli), «Administração de sociedades comerciais no Direito Comercial Comparado» (Prof. Luiz Gastão Paes de Barros Leães), "Sociedades mercantis no Direito Comparado» (Prof. Fábio Konder Comparato) e «Títulos societários na Direito Comercial Comparado» (Prof. Nelson Abrão). A inclusão destas disciplinas no curso de pós-graduação, sob a responsabilidade dos ilustres professores indicados, tem possibilitado o alargamento da visão dos freqüentadores dos cursos e a formação de uma nova geração de comparativistas.

O elevado nível do juscomparativismo brasileiro criou condições para o aparecimento de novos institutos e academias para congregar os aficionados pela matéria. Assim é que, em 1980, ocorreu a fundação da "Academia Internacional de Jurisprudência e Direito Comparado», no Rio de Janeiro. Sob a liderança do Prof. Custódio de Azevedo Bouças, seu atual presidente, a Academia reúne eminentes juscomparativistas brasileiros e estrangeiros. Correndo o risco de não 
mencionar nomes de destaque, registramos dentre os associados $\mathrm{Ha}$ roldo Valladão, José Eduardo Prado Kelly, Afonso Arinos de Melo Franco, Pedro Calmon, Orlando Gomes, Pinto Ferreira, Machado Paupério, Paulino Jacques e Alfredo Buzaid, do lado nacional, e Marc Ancel, Alfred Rieg, Jacques Robert, Roland Drago, Alain Chosi, Yves Gaudemet e Michel Fromont, do estrangeiro. A entidade já possui sede própria, biblioteca especializada e promove reuniões semanais para a discussão de assuntos ligados à Ciência Jurídica e, em especial, sobre Direito Comparado. Ainda conta com uma publicação, o «Mensageiro Jurídico», para a divulgação das atividades e publicação de artigos e estudos sobre matéria jurídica.

Outra entidade que atesta o interesse pelo Direito Comparado no Brasil é o «Instituto de Direito Comparado Luso-Brasileiro», com sede no Rio de Janeiro. Criado em 1981, tem por objetivo a promoção do intercâmbio científico entre o Brasil e Portugal no campo jurídico, através da realização de reuniões periódicas entre os juristas interessados no estudo comparativo dos direitos dos dois países. Dentre os integrantes podem ser lembrados os nomes de Orlando Gomes, Haroldo Valladão, Caio Mário da Silva Pereira, R. Limongi França e Francisco dos Santos Amaral Neto (Presidente do Conselho Diretor da Entidade), do lado brasileiro, e A. Ferrer Correia, Antunes Varela, Diogo Leite de Campos e Francisco Pereira Coelho, do português. O Instituto, em que pese a sua juventude, já conta com uma publicação, a «Revista de Direito Comparado Luso-Brasileiro». Além de outras promoções científicas já realizadas, promoverá em setembro do próximo ano (1984) o «V Simpósio de Direito Comparado Luso-Brasileiro» e o «Congresso Luso-Brasileiro de Propriedade», prevendo-se a participação de expressivas figuras do cenário jurídico nacional e estrangeiro.

A realidade é que o juscomparativismo no Brasil fincou raizes profundas, sendo reconhecido internacionalmente como um importante centro de estudos. $O$ interesse pelo assunto determinou a realização de trabalhos do mais alto nível, conforme apontamos acima na apresentação sumária da literatura brasileira do Direito Comparado, bem como a criação de instituições especializadas para congregar os aficionados. Prevê-se, inclusive, a ampliação do esforço juscomparativista em direção a novas áreas e países.

\section{Considerações finais}

O panorama apresentado permite-nos avaliar o alcance e o significado do estudo e da pesquisa jurídica comparativa na atualidade. A partir das manifestações iniciais, registradas na Antiguidade, verificou-se a formação paulatina do corpo de conhecimentos científicos, que hoje conhecemos por Direito Comparado. Da noção limitada do objeto do Direito Comparado, restrito ao simples exame dos direitos estrangeiros, evoluiu-se no sentido de uma preocupação mais ampla 
que, em nossos dias, atinge o fator jurisprudencial e a Ciência Jurídica, visando a internacionalização dos seus princípios.

A pesquisa juscomparativista, conforme acentuam os mais abalizados especialistas no assunto, possibilita a abertura de novos caminhos à Ciência do Direito que, com base nos progressos alcançados pela contínua atividade científica dos seus cultores, poderá atender melhor as necessidades criadas pelo vertiginoso ritmo de mudança do mundo contemporâneo e à problemática e complexa comunidade mundial inexoravelmente inter-relacionada nos diversos planos da existência humana.

O amadurecimento científico registrado no século em curso coloca o Direito Comparado como um valioso instrumento para se obter um melhor entendimento no plano das relações internacionais. Através da análise e comparação de ordenamentos jurídicos distintos, será possível não só encontrar os seus pontos comuns e evidenciar as suas particularidades como, também, captar as características básicas dos diversos países, o espírito do seu povo, as suas instituições, o seu projeto histórico, etc. $\mathrm{O}$ conhecimento recíproco favorecerá a criação de canais de comunicações em bases mais sólidas, amplas e autênticas, que poderão eliminar as atuais controvérsias e disputas existentes no campo das relações internacionais, cujas dimensões ainda não foram suficientemente avaliadas pelos homens. O cultivo do Direito Comparado representa, assim, um esforço em direção à paz mundial.

$\dot{E}$ mister para que o Direito Comparado realize a sua missão, que haja uma maior divulgação da importância do estudo e da pesquisa juscomparativa. Além da produtiva atuação das instituições dedicadas à matéria no plano nacional e internacional, principalmente com a realização de congressos, da publicação e divulgação de obras especializadas, do ensino em nível de pós-graduação, e do esforço pessoal de muitos precursores passados e presentes, deve-se procurar novas formas de incentivar ainda mais o interesse pelo estudo do Direito Comparado. E Um desafio para os juscomparativistas e especialistas em ensino do Direito.

\section{Bibliog rafia}

1. ANCEL, Marc. Utilidade e métodes do Direito Comparado; elementos de introdução geral ao estudo comparativo dos direitos. Porto Alegre, Sérgio Antonio Fabris, 1980.

2. ASCARELLI, Tullio. Problemas das sociedades anônimas e Direito Comparado. São Paulo, Saraiva, 1945.

3. BeVIlaquA, Clóvis. Resumo das liçōes de legislação comparada sobre o Direito Privado. $2^{\text {s }}$ ed. Bahia, Magalhães, 1897.

4. CAStro Mendes, João. Direito Comparado. Lisboa, s.c.p., 1982-1983.

5. DAvid, René. Traité elémentaire du Droit Civil Comparé. Paris, Librairie Générale de Droit et Jurisprudence, 1950.

6. - Os grandes sistemas de Direito Contemporâneo; Direito Comparado. 24 ed., Lisboa, Meridiano, 1978. 
7. LEME, Lino de Morais. Direito Civil Comparado. São Paulo, Revista dos Tribunais, 1962.

8. MONTEIRO, João. Universaliząão do Direito; Cosmópolis do Direito, Unidade do Direito. São Paulo, Duprat, 1906.

9. RODI RE, René. Introduction au Droit Comparé. Paris, Dalloz, 1979.

10. Santos, José Nicolau dos. Direito Comparado e Geografia Juridica. Separata do vol. II dos Estudos Jurídicos em honra de Soriano de Souza. Recife, Ministério da Educação e Cultura/Universidade do Recife/Faculdade de Direito, 1962.

11. SILVA PEREIRA, Caio Mário. Direito Comparado e o seu estudo. Separata do vol. II dos Estudos Jurídicos em honra de Soriano de Souza. Recife, Ministério da Educação e Cultura/Universidade do Recife/Faculdade de Direito, 1962.

12. SOUTO, Cláudio. Introdução ao Direito como ciência social. Rio de Janeiro, Tempo Brasileiro, Universidade de Braślilia, 1971.

13. VAlladxo, Haroldo. O estudo e o ensino do Direito Comparado. Revista Forense. Rio de Janeiro, Forense, 1970. Vol. 231.

14. - Direito Comparado. Enciclopédia Saraiva de Direito. São Paulo, Saraiva, 1977. Vol. 25.

15. VITA, Luís Washington. Introdução à Fisolofia. Săo Paulo, Melhoramentos, 1964. 